\title{
UMA REVISÃO/DISCUSSÃO SOBRE A FILOSOFIA DA CIÊNCIA ${ }^{1}$
}

\author{
Reinaldo Furlan ${ }^{2}$ \\ FFCLRP - Universidade de São Paulo
}

\begin{abstract}
RESUMO: O objetivo deste artigo é introduzir e estimular a reflexão sobre a natureza do conhecimento científico. A intenção não é dogmática, no sentido de dizer o que é a metodologia científica, mas apresentar questões que estão na base da discussão de sua fundamentação e que rompem com a aparente certeza do senso comum sobre a natureza do conhecimento científico: a relação entre história da ciência interna e externa, a crítica à noção de indução, o papel da teoria na observação, o princípio de verificação. Privilegia-se nessa apresentação as duas principais teorias que polarizaram as discussões da filosofia da ciência nas últimas décadas, as teorias de Popper e de Kuhn sobre os fundamentos da metodologia científica.
\end{abstract}

Palavras-chaves: filosofia da ciência; metodologia científica.

\section{ONE REVISION/DISCUSSION ABOUT THE PHILOSOPHY OF SCIENCE}

ABSTRACT: The objective of this paper is to stimulate the reflection on the nature of scientific knowledge. The intention is not dogmatic, in the sense of saying what is scientific methodology, rather to present the following points that are the basis for the discussion of its foundation and break up with the apparent certainty of the common sense on the nature of scientific knowledge: (1) the relationship among internal and external science history, (2) the critic to the induction notion, (3) the role of theory in observation, (4) the principle of verification. In that presentation it is privileged the two main theories that polarized the discussions of philosophy of science in the last decades: the theories of Popper and Kuhn on the scientific methodology foundations.

Key-words: philosophy of science; scientific methodology

A História da Ciência procura analisar na sua sequiência os fatos científicos: os contextos das descobertas, as crises teóricas, as substituições e desenvolvimento de teorias. É comum serem encontradas duas perspectivas contrárias de análise do desenvolvimento histórico do conhecimento científico, uma que corresponde à história interna e outra à externa. A título de introdução, pode-se dizer que os adeptos da história interna concebem o desenvolvimento do conhecimento a partir de questões intrínsecas à racionalidade científica, e concedem à história externa apenas o papel de circunstanciá-lo. Pressões externas à evolução da Ciência, como a alocação de recursos para áreas de interesses econômicos ou sociais, podem limitar ou promover a construção do

\footnotetext{
' Artigo recebido para publicação em 05/2002; aceito em 10/ 2002

2 Endereço para correspondência: Reinaldo Furlan, Departamento de Psicologia e Educação, Faculdade de Filosofia, Ciências e Letras de Ribeirão Preto, USP, Av. Bandeirantes, 3900, Monte Alegre, Ribeirão Preto, SP. Cep 14040-901, E-mail: reinaldof@ffclrp.usp.br
}

conhecimento em determinadas áreas, mas este obedece a uma lógica própria que independe desses e de outros fatores externos a sua racionalidade. Os adeptos da história externa, em contrapartida, advogam que a lógica ou racionalidade científica não apresenta razões suficientes para o desenvolvimento do conhecimento, que em última instância repousa em fatores psicossociais presentes no seu exercício.

Pretende-se mostrar que a História da Ciência não pode mais ser vista como uma coleção de práticas e de teorias bem sucedidas e acumulativas, uma imagem freqüentemente passada pelos manuais, mas que a ciência está prenhe de questões filosóficas, tanto quanto a reflexão filosófica é banhada de História, e que não se deve nem reduzir a História da Ciência à Filosofia - quando se trata de explicitar o sentido disso que se chama ciência - nem de recusar, em contrapartida, a discussão fílosófica de seus termos. Espera-se que a exposição e discussão de alguns dos termos freqüentemente associados à prá- 


\section{Reinaldo Furlan}

tica científica possam servir de ilustração e incentivar a reflexão.

O foco estará nas ciências naturais, particularmente a física, cujo sucesso histórico fez dela o modelo mais destacado ${ }^{1}$. E há um ganho geral em iniciar a reflexão a partir da noção mais canônica de ciência, a concepção mais aceita de conhecimento.

\section{A Crítica ao Conceito de Indução}

Um dos termos mais usados para distinguir a ciência de outras atividades seja o de que o seu conhecimento está baseado em observação.

Francis Bacon, teórico lembrado freqüentemente, dizia que o método científico é um método de observação, que deveria ser rigorosa e isenta de preconceitos. Bacon identificava quatro estados ou atitudes perniciosas ao conhecimento científico: 1- a tendência à generalização apressada, própria da natureza humana, a que deu o nome de Ídolos da Tribo; 2 - atitudes referentes aos fatos, provenientes da educação, a que deu o nome de Ídolos da Caverna; 3- as distorções dos significados das palavras no uso vulgar, a que deu o nome de Ídolos da Praça do Mercado; 4- os dogmas e métodos provenientes da filosofia, aos quais deu o nome de Ídolos do Teatro.

Bacon acreditava na possibilidade de uma experiência despida dessas interferências que distorciam seu verdadeiro sentido, a ser conquistado pela atitude científica. Cautela na observação, suspensão das idéias recebidas da educação, cautela e precisão no uso da linguagem, e o desenvolvimento de experiências criadas especificamente para atender aos fins da interrogação científica (o que, se não representava uma novidade estrito senso na época, marcaria cada vez mais a prática da ciência posterior), eram os ingredientes do receituário baconiano para a atitude científica. A partir dessas observações a ciência deveria inferir gradualmente os princípios mais gerais da natureza. Sendo assim, o conhecimento científico poderia ser certo e seguro, e por isso ele não admitia hipóteses na Ciência, sobretudo aquelas da metafísica que visavam às razões últimas das coisas, e que ultrapassavam as passíveis de experimentação.

\footnotetext{
' A abordagem das ciências humanas demandaria a investigação de outro tipo de material que ultrapassaria os limites deste artigo. A biologia mereceria também uma discussão à parte, mas pela mesma razão fica de fora.
}

Popper $(1959,1999)$ não foi o único, nem o primeiro, a realizar a crítica do princípio da indução na expliçitação do método científico, mas a sua talvez seja a mais popular entre nós. O autor aceita, do ponto de vista lógico, a crítica de Hume ao princípio de indução, isto é, de que a partir da observação da regularidade de determinados eventos, não é possível prever com alto grau de certeza a mesma sucessão de eventos. Do ponto de vista lógico, não é necessário que assim seja: não é porque se viu 1000 gansos brancos que o próximo também será branco, não é porque o sol se levanta e se põe a cada dia, que se pode prever que amanhã o mesmo ocorrerá. Tais fatos não são necessários do ponto de vista lógico, uma vez que do particular (ocorrências datadas e situadas) não se pode inferir com necessidade o universal, que é o que interessa à ciência na elaboração das leis da experiência.

Isso fica bem claro na crítica de Hume à noção de causalidade, um dos pontos interessantes e duradouros de seu pensamento na Filosofia da Ciência. Embora Popper não concorde com a análise psicológica humeana da experiência, pois assinala que com animais e crianças basta uma única experiência para se estabelecer o vínculo de sucessão entre alguns eventos; o fato é que o desafio de Hume aos racionalistas da época continua vivo até hoje, isto é a impossibilidade de descobrir baseado apenas na razão porque o evento " $B$ " sucede sempre ao evento "A", porque, por exemplo, os corpos se atraem, ou a cafeína dilata as artérias, ou tal vírus de determinada composição química é nocivo ao organismo, ou o amido é assimilado pelas células. Tudo o que se sabe é que assim tem ocorrido, mas não porque tem que ser assim. Em outros termos, se o pensamento pudesse descobrir as razões intrínsecas à sucessão dos eventos, estabeleceria, dadas as mesmas condições, leis necessárias; na sua falta, apenas se apoia no costume, de que de fato as coisas têm se sucedido assim.

Mas a crítica interessante de Popper ao princípio de indução não parece ser essa do ponto de vista lógico, porque a crença na regularidade necessária dos fenômenos, fundada ou não logicamente, é a condição de possibilidade da própria ciência. Fossem os eventos sempre aleatórios na sua sucessão, não caberia estabelecer lei alguma, e talvez a própria 
vida não acontecesse. $O$ caos se encontra, nesse sentido, na antípoda da ciência, cuja existência depende, pois, de se poder estabelecer (arbitrariamente ou não, do ponto de vista lógico) a ordem dos fenômenos. É isto que leva a propor enunciados universais da ciência que se testa, depois, através da experiência.

A crítica mais interessante consiste em afirmar que a indução é um mito, não apenas do ponto de vista lógico, mas da prática científica. Popper diz que não se espera a repetição ou a sucessão de eventos para, então, indutivamente, chegar a conclusões sobre os problemas. Salta-se para hipóteses arriscadas que são testadas depois passo a passo. Sobretudo, diz ele, a experiência científica não consiste na observação aleatória e genérica do que acontece - o que não levaria a parte alguma -, mas ela diz respeito à organização de experimentos que visam responder às perguntas e testar as hipóteses.

É a razão, portanto, que se adianta na formulação de questões, de hipóteses e no planejamento de experimentos para a sua solução. Ou seja, ninguém inicia uma observação científica sem uma teoria, e basta a seleção de alguns elementos que se considera relevantes para o problema, para indicar a sua presença, ainda que rudimentar. A possibilidade de uma experiência pura, na qual as idéias surgissem das impressões sensíveis, independentes de qualquer interpretação, é um mito, e nele se apóia o princípio da indução no conhecimento científico. Ora, segundo Popper, a motivação para esse mito decorre da intenção de se demarcar o conhecimento científico de enunciados pseudo-científicos, apoiando-os na observação. Mas, segundo ele, a Astrologia também se baseia na observação (dos astros) e nem por isso seus enunciados são considerados científicos. Um critério de demarcação deve existir, de modo a contornar o problema lógico da indução, isto é, não se pode logicamente inferir proposições universais a partir de particulares, mas é possível deduzir proposições particulares de universais. Assim, a ciência consiste de conjecturas ou enunciados universais na solução dos problemas, e a partir deles fazer a dedução da ocorrência de.fatos que, caso não ocorram, contradizem o enunciado geral, falsificando a teoria proposta.

Popper contorna, assim, o problema da indução colocado por Hume, de que não é possível inferir proposições universais de experiências particulares, ao mesmo tempo em que separa enunciados científicos de não científicos. $O$ aspecto da crítica, pois, a ser enfatizado é esse de que o método indutivo estaria na origem das teorias científicas, ignorando a importância da presença de hipóteses e teorias para a organização da experimentação.

Hempel (1981) também aponta para isto, embora de forma mais condescendente com o método indutivo, enfatizando que os dados empíricos só podem ser relevantes para uma hipótese, e não para um problema, o que fica claro quando ele analisa a investigação da febre puerperal pelo médico húngaro I. Senemelweis no hospital geral de Viena entre os anos de 1844 a 1848.

Tratava-se de uma doença, geralmente fatal, após o parto na maternidade do hospital, que contava com duas alas na maternidade, uma atendida por professores e alunos de medicina, e outra por enfermeiras parteiras, sendo os números significativamente maiores na ala dos médicos e estudantes. Curiosamente, mulheres que davam à luz a caminho da maternidade, para depois serem atendidas na ala dos médicos, em geral não contraíam a doença. Senemelweis começou a investigar as diferenças entre as duas alas, para descobrir a causa do mal. Não aceitava, naturalmente, que a causa estivesse no médico simplesmente pelo fato de ser médico, e não uma enfermeira. $O$ problema da doença encontrava-se, assim, na presença de inúmeros dados empíricos que, na ausência de hipóteses, representavam apenas uma multiplicidade de informações sem nexo.

Várias hipóteses foram consideradas. A primeira foi referente ao padre estar sempre na ala dos médicos, solicitado para dar a extrema-unção, ou seja, a presença do "símbolo da morte" poderia ser nociva à recuperação das outras pacientes; eliminou-se a passagem do padre, mas o problema persistiu. Em seguida, investigou-se a questão da diferença na posição de realização do parto, já que na ala dos médicos, ele era sempre feito com a paciente deitada, e na outra ala, geralmente de cócoras; eliminada a diferença não houve mudança no aparecimento da doença. Certo dia, um colega médico acidenta-se com o bisturi, realizando a autópsia de uma das vítimas, e 


\section{ReinaldoFurlan}

morre (não se conhecia, na época, o papel dos microorganismos nas doenças). Senemelweis pensa, então, na hipótese de que o bisturi utilizado nas autópsias e nas aulas (o que não ocorria na ala das enfermeiras, e nem era o caso para a maioria das mulheres cujos filhos nasciam a caminho da maternidade) era o agente transmissor da doença, causada por "matéria cadavérica contaminada". A higienização dos bisturis ocasionou a redução do número de mortes, mas a diferença entre as alas ainda permanecia significativa, até se descobrir, finalmente, que mesmo pacientes contaminados podiam transmitir a doença, e que os bisturis deveriam ser higienizados para cada paciente. Chegou-se à conclusão que a causa da doença seria a "matéria pútrida ou contaminada retirada de um organismo vivo ou morto".

Hempel chamá a atenção para o fato de que, sem a criação de hipóteses, o método indutivo não pode ser operante, isto é, que ele depende de hipóteses que discriminam elementos relevantes para o problema, para então verificá-las indutivamente.

Mas, como para Popper a passagem das experiências (ou problemas) para as teorias não pode ser justificada indutivamente (lógica da descoberta), jamais se garante que as teorias sejam verdadeiras, mesmo depois de sua aprovação através de testes realizados para sua avaliação, uma vez que o problema da indução se colocaria novamente: seria preciso a realização de todos os casos que colocassem em teste a teoria, o que é impossível de ser feito (ter-seia que abarcar o universo em sua extensão e duração), restando assumir que enquanto os testes ou experiências não contrariam as teorias, elas continuam valendo como conhecimento.

O critério popperiano de demarcação da ciência passa, assim, a exigir que toda teoria com pretensão de cientificidade possibilite a dedução de proposições que, se ocorrerem, a falsifiquem, ou, que proíba o aparecimento de certos fatos, sendo tanto melhor quanto mais próibe, ou maior seu conteúdo empírico.

É por não especificar condições de falsificação que a Psicanálise, aos olhos de Popper, não é ciência, aproximando-se mais da linguagem dos mitos, e não é virtude, visto que seu poder de explicação não é acompanhado da proibição da ocorrência de fatos que a falsifiquem. A Psicanálise explica muito, mas é irrefutável e não pode ser testada ou confrontada. O marxismo, ao contrário, fixou as condições em que sua teoria seria refutada, através da necessidade de desenvolvimento do modo de produção capitalista para a ocorrência da revolução socialista; no entanto, a união soviética pulou essa etapa, o que teria refutado a teoria. Mas, segundo Popper, os marxistas fizeram modificações ad hoc para acomodar a teoria aos fatos, alterando hipóteses básicas que comprometeram o seu caráter lógico-dedutivo.

Para Popper existe a possibilidade de criação de hipóteses auxiliares, na tentativa de se salvar uma teoria, mas as alterações devem levar à previsão de fatos novos (falseáveis) e não ao enfraquecimento da estrutura lógica da teoria. Um dos exemplos na história da ciência, nesse sentido, foi a confirmação da teoria newtoniana da gravitação com a descoberta do planeta Netuno. Segundo Chalmers (1993)

"as observações do século XIX sobre o mo-
vimento do planeta Urano indicavam que sua
órbita se afastava consideravelmente da que
fora prevista com base na teoria gravitacional
de Newton, colocando assim um problema
para esta teoria. Numa tentativa de superar
a dificuldade, foi sugerido, por Leverrier na
França e por Adams na Inglaterra, que exis-
tia um planeta que ainda não fora detectado
nas adjacências de Urano. A atração entre o
planeta hipotético e Urano deveria explicaro
afastamento deste último de sua órbita pre-
vista inicialmente. Esta sugestão não era ad
hoc, como os eventos demonstrariam. Seria
possível calcular a adjacência aproximada do
planeta conjectural se ele tivesse um tama-
nho razoável e fosse responsável pela per-
turbação da órbita de Urano" (p.82).

A descoberta de Netuno, nesse sentido, não só corroborou a teoria, como trouxe um conhecimento novo. Em síntese, não há para Popper lógica da descoberta científica, já que se nega o princípio da indução, há apenas a da justificação. O processo de descoberta é objeto para ciências empíricas (psicologia ou sociologia), não para uma epistemologia que cuida apenas do caráter lógico da teoria. Tudo vale na formação de teorias: insights, intuição, imagina- 
ção, observações controladas, e até mesmo sonhos que sugerem soluções para o problema pesquisado, como teria sido o caso da descoberta da fórmula química do benzeno, por Kekulé. Embora Popper procure enfatizar o caráter ativo e organizador da razão, não é objeto da epistemologia perguntar como se chega às hipóteses e conclusões, mas distinguir enunciados científicos de pseudo-científicos através da lógica da justificação: pode-se deduzir de enunciados gerais os particulares (ocorrência de fatos) e confrontá-los com a experiência. A grande questão da epistemologia é a da demarcação do conhecimento, e só uma lógica da justificação pode fornecer a solução desse problema.

O pensamento de Popper é uma das expressões contundentes da passagem da física newtoniana para a de Einstein. O Deus de Descartes, que garantia como critério de verdade a evidência do pensamento, foi substituído por uma noção de conhecimento mais dinâmico e provisório, sendo o conhecimento humano também limitado, mas noutro sentido: de um lado porque existem coisas que o entendimento não pode conhecer com clareza, como, por exemplo, a união da alma e do corpo, e de outro porque o conhecimento é inesgotável dada a infinitude do universo a conhecer. Mas, o que se sabe de forma clara e distinta é certo e indubitável, o que implica em ter o conhecimento concebido como uma construção progressiva de certezas. Ora, o conhecimento científico questionou justamente a idéia de verdades adquiridas, de forma que parecem se multiplicar as possibilidades de variação das perspectivas sobre o real, conquanto se possa, ainda, sustentar a idéia de um progresso no conhecimento. Em outros termos, a história da ciência não podia mais ser vista como um processo de acumulação sem sobressaltos e rupturas.

\section{A Razão Científica em Questão}

Um dos teóricos proeminentes do século $\mathrm{XX}$, que enfatizou as rupturas na história da ciência, foi sem dúvida Thomas Kuhn. Seu pequeno, mas estimulante livro A Estrutura das Revoluções Científicas (1992), constituiu-se em um marco de referência para filósofos e historiadores da ciência e sua obra representa, em relação à de Popper, um enfoque mais voltado para as práticas das comunidades científi- cas, do que propriamente para os fundamentos lógicos de suas teorias. Os críticos de Popper o acusam de propor um padrão metodológico que não corresponde à prática da ciência e ele, por sua vez, insistia no papel ativo da crítica metodológica como contribuição da epistemologia à pratica da ciência. Esse caráter explícito de orientação não se encontra na obra de Kuhn, que se propõe, sobretudo a um relato histórico do desenvolvimento da ciência. É verdade que Feyerabend (1977) levanta a questão de saber se a obra de Kuhn aconselha ou não o cientista à determinada conduta, afírmando que ele é ambíguo quanto a isso. De fato, ao julgar que é um sinal de maturidade da ciência a ausência de discussões a respeito de suas teorias, o que propicia o desenvolvimento exaustivo do paradigma, (a acumulação de conhecimento sobre a realidade no interior de determinada visão de mundo), Kuhn parece incentivar a atitude acrítica do cientista ${ }^{2}$. De qualquer forma, não se encontra em Kuhn, como em Popper, a declaração de intenção de orientação da prática científica através da análise metodológica. Ou seja, a obra do primeiro é de caráter mais histórico ou descritivo do que a do segundo. No posfácio de $1969^{3}$, Kuhn enfatiza, inclusive, que se tivesse que rescrevê-la, começaria pela análise das estruturas das comunidades científicas, o que merecia cada vez mais a atenção dos historiadores e sociólogos da ciência.

A obra de Kuhn pode ser vista como uma crítica à visão popperiana de ciência. Três pontos podem ser destacados: 1) a tese da incomensurabilidade das teorias, vista por seus críticos como uma afirmação do relativismo ou do irracionalismo na história da ciência, 2) a necessidade da ciência normal, que representa a possibilidade de exploração máxima de um paradigma, isto é, de seu desenvolvimento teórico e instrumental 3) a presença constante de anomalias nas teorias científicas, com o que se critica, do ponto de vista histórico, a metodologia falsificadora da ciência.

Antes de tudo, é preciso deixar clara a noção

\footnotetext{
${ }^{2}$ Como diz Feyerabend no Coloquio Internacional sobre Filosofia da Ciência, realizado em Londres em 1965, que entre outros temas se propunha, justamente, a discutir as diferenças entre os pensamentos de Kuhn e Popper sobre ciência (Feyerabend, apud Lakatos \& Musgrave, 1979). No mesmo colóquio, o título da intervenção de Popper é no mesmo sentido: "A Ciência Normal e seus Perigos".

3a publicação original é de 1962
} 
que popularizou Kuhn na história das ciências, que é a de "paradigma", que representa o pressuposto comum de uma comunidade científica, que envolve determinada concepção de mundo e um conjunto de regras de procedimentos de pesquisa. A concepção de mundo abarca desde uma visão mais geral acerca da realidade, até teorias específicas da área de pesquisa. Os manuais de ciência são um bom exemplo dessas teorias compartilhadas pelos membros de uma comunidade científica, que todo ingressante deve assimilar naturalmente em sua formação. Regras de procedimento são aquelas aceitas, como metodologia de coleta de dados, apresentação de resultados, utilização de instrumentos. Em síntese, o paradigma é a base comum de acordo da comunidade científica, a partir da qual se desenvolvem suas pesquisas e a discussão de suas questões, e é o que Kuhn chama de teoria, no sentido amplo do termo, para enfatizar que a ciência normal não a toma como foco, isto é, não está interessada em discuti-la, mas em resolver quebra-cabeças que são questões presentes no desenvolvimento da aplicação do paradigma à realidade. Kuhn $(1962,1992)$ diz:

"A ciência normal não tem como objetivo trazer à tona novas espécies de fenômeno; na verdade, aqueles que não se ajustam aos limites do paradigma freqüentemente nem são vistos (...) Em vez disso, a pesquisa científica normal está dirigida para a articulação daqueles fenômenos e teorias já fornecidos pelo paradigma (...) Talvez essas características sejam defeitos. As áreas investigadas pela ciência normal são certamente minúsculas; ela restringe drasticamente a visão do cientista. Mas essas restrições, nascidas da confiança no paradigma, revelaram-se essenciais para 0 desenvolvimento da ciência. Ao concentrar a atenção numa faixa de problemas relativamente esotéricos, o paradigma força o cientista a investigar alguma parcela da natureza com uma profundidade e de uma maneira tão detalhada que de outro modo seriam inimagináveis" (p.45)

Nesse sentido,

"a ciência normal, atividade que consiste em solucionar quebra-cabeças, é um empreendimento altamente cumulativo, extremamente bem sucedido no que toca ao seu objetivo, a ampliação contínua do alcance e da precisão do conhecimento científico" (idem, p.77).

Portanto, uma opção metodológica que se revelou frutífera. Kuhn alude, mais à diante, a um critério mais racional do que esse na justificação dessa opção:

\footnotetext{
"Uma vez que a natureza é muito complexa e variada para ser explorada ao acaso, esse mapa é tão essencial para o desenvolvimento contínuo da ciência como a observação e a experiência" (p.143).
}

A profusão de teorias e de discussões metodológicas representaria apenas o período préparadigmático de uma ciência, que só se desenvolve com o estabelecimento de um paradigma e a cessação dessas discussões, isto é, a partir do consenso sobre o método e a natureza do objeto de estudo.

Como o objetivo da obra de Kuhn é, em primeiro lugar, a apresentação histórica do caráter geral do desenvolvimento da ciência, críticas à sua apresentação da ciência normal teriam de ocorrer na discussão da própria história. De fato, o que se contrapõe à sua visão é que, a despeito de tocar em aspectos importantes, ela ignora ou elide a ocorrência de discussões teóricas no exercício da ciência. Feyerabend (apud Lakatos \& Musgrave, 1.979) cita, contra o monopólio do paradigma, a proliferação de teorias na história da ciência, com pontos de vista diferentes, incompatíveis e até incomensuráveis, cuja interação pode promover a emergência de outras tantas. É o que acontece, segundo ele, entre os pontos de vista da mecânica, da teoria do calor e da eletrodinâmica que derrubaram a física clássica. Portanto, Kuhn teria visto mais ordem do que de fato existe naquilo que chamou de ciência normal. Mas, algo muito importante levantado por ele e imediatamente aceito pelos historiadores e teóricos da ciência, foi a presença comum de anomalias nas teorias científicas, sem que isso represen- 
tasse uma crise; tanto erros de precisão quantitativa ṇa medição dos fenômenos, quanto qualitativa, no sentido de incompatibilidade da teoria com a experiência ${ }^{4} E$ nada disso representa, necessariamente, uma crise e teria sido uma das críticas mais importantes ao modelo metodológico de desenvolvimento das ciências proposto por Popper que enfatiza a tentativa de falsificação de uma teoria como a mola propulsora do desenvolvimento da ciência. Enquanto conselho metodológico, a idéia pode ser muito atraente, mas a questão é saber em que medida ela expressa o desenvolvimento histórico da ciência, e mesmo se o propicia, caso seja aceita.

O lado atraente - Popper salienta dois aspectos no desenvolvimento da ciência: a) conjecturas téricas arriscadas b) refutação de teorias estabelecidas. Chalmers $(1993)^{5}$ afirma que não se aprende, ou se aprende muito pouco, com conjecturas cautelosas, porque estas mais confirmam o conhecimento atual do que possibilitam avanços significativos nas teorias; elas são sempre conservadoras. Conjecturas arriscadas, ao contrário, rompem com a maneira comum de pensar, e por isso, quando confirmadas, representam avanços significativos. Assim, quando as previsões de Einstein sobre a curvatura da luz sob efeito de forte atração gravitacional foram confirmadas por Eddington, a teoria passou por um importante teste de falsificação que corroborou o seu avanço em relação à concepção anterior. Na refutação das teorias a relação se inverteria, isto é a negação das arriscadas não ensina nada, obviamente, mas quando ocorre a refutação das bem estabelecidas, que passaram por muitos testes de "verificação", Chalmers (1993) diz que:

"um novo próblema, auspiciosamente bem distante do problema original resolvido, emergiu. Este novo problema pede a invenção de novas hipóteses, seguindo-se a crítica e testes renovados" (p.73)

Assim,

"a falsificação da teoria de Einstein permanece um desafio para os físicos modernos.

4 (Feyerabend, em Contra o Método, 1977, explora com particular atenção essas inconsistências).
Seu eventual sucesso assinalaria um novo passo na direção do progresso da física" (idem, p.76-77).

Daí a insistência de Popper nas tentativas de falsificação de teorias bem estabelecidas, pois ela é a responsável pelo avanço do conhecimento. Ou seja, um falsificador não está interessado em preservar teorias, mas em refutá-las.

Não é difícil notar que Popper privilegia os momentos de crise ou ruptura na história das ciências. Como ele enfatiza no prefácio de Conjecturas e Refutações (1963, s/d), aprende-se com os erros, e é assim que a ciência progride. Kuhn, por sua vez, fez notar primeiro que, dessa forma, elide-se o cotidiano da prática científica, muito mais voltada para atividades "corriqueiras" de solução de quebra-cabeças no interior do paradigma, o que ressalta a importante relação da ciência com o desenvolvimento de tecnologias ${ }^{6}$.Em segundo, que os grandes acontecimentos na história da ciência não são decisivos no sentido em que Popper procura mostrar, não sendo o destino de uma teoria científica jogado "em uma ou duas rodadas de cartas", mas muito comum a presença de anomalias na sua comparação com a realidade, interpretadas ora como um problema de quebra-cabeças, isto é, solucionáveis no interior do próprio paradigma, ora simplesmente ignoradas e que portanto não existem experimentos cruciais no desenvolvimento da ciência.

Esse ponto da teoria de Kuhn foi muito bem desenvolvido por Lakatos, que propôs, em substituição ao critério popperiano de falseabilidade, a idéia de programas de investigação como metodologia das teorias científicas ${ }^{7}$, que consiste em um núcleo teórico que deve orientar as pesquisas futuras para 0 seu desenvolvimento. Esse direcionamento é indicativo e proibitivo ao mesmo tempo. A heurística positiva representa o primeiro aspecto, e dirige as pesquisas no sentido de aplicação da teoria à realidade, conduzindo, se o programa tem êxito, à desco-

\footnotetext{
' Cuja obra, aliás, representa uma introdução muito clara das várias vertentes contemporâneas de discussões da metodologia e do desenvolvimento histórico da ciência.

" (Em outros termos, Popper dirige os "holofotes" para grandes acontecimentos em detrimento do cotidiano da história)

7 "O Falseamento e a Metodologia dos Programas de Pesquisa Científica" (Lakatos \& Musgrave, 1979)
} 
berta de fatos novos e ao desenvolvimento de teorias auxiliares. A heurística negativa diz respeito ao aspecto 2, e consiste na proibição de se questionar o núcleo básico da teoria, representando a tenacidade do programa, sua persistência, a despeito das anomalias ou incongruências com a experiência. A teoria não é falsificável no núcleo básico, está protegida por um cinturão de hipóteses auxiliares, "que tem de suportar o impacto dos testes e ir se ajustando e reajustando, ou mesmo ser completamente substituído, para defender o núcleo assim fortalecido" (Lakatos \& Musgrae, 1979, p.162).

Um programa de pesquisa é progressivo quando, ao menos intermitentemente, leva à descoberta de fatos novos, isto é, enquanto seu desenvolvimento teórico antecipa o empírico; é degenerativo se não consegue oferecer mais do que explicações posthoc. De qualquer forma, seu sucesso ou fracasso não pode ser decretado por esta ou aquela experiência crucial. Daí Feyerabend (1977) concluir, citando Lakatos, que

"surgida uma teoria nova, não cabe, de imediato, recorrer aos padrões costumeiros para decidir se ela sobreviverá ou não. Nem gritantes incoerências internas, nem óbvia ausência de conteúdo empírico, nem amplo conflito com resultados experimentais deve impedir-nos de conservar e aperfeiçoar pontos de vista que, por esta ou aquela razão, nos agrade" (p.287).

Há um exemplo hipotético imaginado por Lakatos, aparentemente à luz da descoberta do planeta Netuno, que ilustra bem a idéia de tenacidade de um programa de pesquisa, e a recusa do critério falsificador como metodologia da ciência. Chalmers (1993) diz:

"A história é sobre um caso imaginário de mau comportamento planetário. Um físico da era pré-einsteiniana toma a mecânica de Newton e sua lei da gravidade, $\mathrm{N}$, como as condições iniciais aceitas, $\mathrm{I}$, e calcula, com sua ajuda, o percurso de um pequeno planeta recentemente descoberto, p. Mas o planeta desvia-se do percurso calculado. Por acaso, nosso físico considera que o desvio era proibido pela teoria de Newton e portanto que, uma vez estabelecido, refuta a teoria N? Não. Ele sugere que deve haver um desconhecido planeta p', que perturba o percurso de p. Ele calcula a massa, orbita, etc. de seu hipotético planeta e pede então a um astrônomo experimental que teste sua hipótese. O planeta p' é tão pequeno que mesmo os maiores telescópios disponíveis não podem observá-lo; o astrônomo experimental pede uma verba para construir um ainda maior. Em três anos o novo telescópio está pronto. Se o desconhecido planeta p' for descoberto será uma nova vitória para a ciência newtoniana. Mas não é. E nosso cientista abandona a teoria de Newton e sua idéia de um planeta perturbador? Não. Ele sugere que uma nuvem de poeira cósmica esconde-nos o planeta. Calcula a localização e as propriedades dessa nuvem e pede uma verba de pesquisa para mandar um satélite testar seus cálculos. Se os instrumentos do satélite (possivelmente de tipo novo, baseados numa teoria pouco testada) registrarem a existência da nuvem conjectural, o resultado será visto como uma notável vitória para a ciência newtoniana. Mas a nuvem não é descoberta. O nosso cientista abandona a teoria de Newton, junto com sua idéia do planeta perturbador e a idéia da nuvem que o esconde? Não. Ele sugere que há algum campo magnético naquela região do universo que perturbou os instrumentos do satélite. Um novo satélite é enviado. Se o campo magnético for encontrado, os newtonianos celebrarão uma vitória sensacional. Mas ele não é. Isto é visto como uma refutação da física newtoniana? Não. Ou uma outra engenhosa hipótese é proposta ou... a história toda é enterrada nos valores empoeirados de publicações periódicas e a história nunca mais será mencionada" (p.96-97).

Mas, em certo sentido, Lakatos está mais próximo de Popper do que de Kuhn. Uma das maiores diferenças dele com Kuhn é que, enquanto este privilegia a história psicossocial no desenvolvimento da 
ciência, e aponta incisivamente para a incomensurabilidade dos paradigmas, Lakatos pretende encontrar os fios da racionalidade na história da ciência. A distinção lakatosiana entre história interna e externa da ciência é justamente para marcar essa posição. Ele defende, como Popper, a idéia de um progresso determinado por avaliações racionais na solução de seus problemas e na substituição de teorias. A distinção entre programas progressivos e degenerativos é um indicador de avaliação. As idéias popperianas de maior conteúdo empírico de uma teoria sobre outra, de resistência a testes em que a precedente fracassou, de maior poder explicativo da sucessora são também incorporados pela metodologia lakatosiana.

Ora, a crítica mais comum que se faz a Lakatos é de que a metodologia dos programas de pesquisa não fornece critérios decisivos para a avaliação de teorias. Por um lado, porque não determina o tempo que se deve esperar para sua avaliação; por outro, porque reconhece que teorias degenerativas podem ressurgir ou serem fundidas, e que é muito difícil decidir entre teorias rivais, uma vez abandonado o critério dos experimentos cruciais. Em última instância, Lakatos apela para o "bom senso", e para indicadores como concessão de verbas, frequiência de realização de congressos para a avaliação dos programas de investigação. Mas, com isso, faz uma importante concessão à história externa que contraria o propósito de fornecer critérios mais racionais de avaliação. O próprio "bom senso", como aponta Feyerabend (1977), não é consensual, dependendo muitas vezes da área do pesquisador:

"os juízos básicos de valor aceitos por um experimentalista diferirão dos aceitos por um teórico (basta ler o que escreveram Rutherford, Michelson ou Ehrenhaft a propósito de Einstein) (...) o seguidor fiel de Bohr virá a introdução de modificações na teoria quântica através de prisma diferente de como o verá o adepto de Einstein" (p.307).

Por essas razões, Feyerabend conclui que a metodologia lakatosiana é apenas retrospectivista, não passa de um ornamento verbal, ou seja, não orienta a prática da ciência e, quando muito, auxilia o historia- dor a recompor o desenvolvimento da ciência.

\section{A que se chega?}

Mas diferenças não devem ofuscar congruências nas concepções do método científico.

Há pontos comuns entre Popper e Lakatos, de um lado, e Kuhn, do outro. Um dos principais é o de que enunciados de percepção dependem de teoria. Kuhn enfatiza mais esse ponto do que Popper, mas este também se encontra em sua obra; ele diz que não há experiência pura, uma vez que toda ela é organizada por questões, expectativas e teorias; ele reconhece, inclusive, o importante papel dos mitos na organização da experiência de mundo, quando não era possível partir de teorias mais elaboradas sobre a realidade. Reserva, entretanto, um espaço aos enunciados de observação na avaliação das teorias, uma vez que elas são testadas a partir dos que proíbem.

Enunciados de observação são os termos através dos quais a teoria confronta-se com a realidade, e os básicos são os comumente aceitos; em termos wittgensteinianos, poder-se-ia dizer que a eles não se aplica a gramática da palavra "dúvida", embora possam mudar com as teorias. Popper (1963, s/d) reconhece que não é possível colocar em questão de uma só vez todos os enunciados básicos de realidade, mas enfatiza muito o papel da crítica no processo de conhecimento, que se progride por soluções de problemas e que se pode questionar suposições básicas nesse processo. Acredita, dessa forma, que se avança ontologicamente com a crítica e a substituição de teorias (que se aprende com os erros), e defende a idéia da possibilidade de um conhecimento objetivo, ou de que a aproximação aos fatos vem através das teorias. Isto é, de que há uma verdade objetiva independente das crenças, mesmo que ela represente mais um papel regulador no processo de conhecimento do que um termo conclusivo, já que não se verificam as teorias, apenas se pode aprimorálas no processo de refutação. Em resumo, Popper $^{8}$ recusa o relativismo afirmando a possibilidade de uma discussão racional das teorias, que permite $o$ avanço para estruturas lingüísticas mais amplas e aperfeiçoadas (é possível avaliar racionalmente concepções diferentes de mundo, ou linguagens através das quais

\footnotetext{
Conforme citado por Lakatos e Musgrave (1979) em A Ciência Normal e seus perigos.
} 


\section{Reinaldo Furlan}

se percebe e organiza a experiência). Tais pontos são bem salientados por Chalmers (1993) na sua apresentação da teoria popperiana do conhecimento, quando destaca dois sentidos diversos de "conhecimento" ou "pensamento":

“(1) conhecimento ou pensamento no sentido subjetivo, consistindo de um estado mental, ou da consciência ou de uma disposição a comportar-se ou a agir, e (2) conhecimento ou pensamento num sentido objetivo, consistindo em problemas, teorias e argumentos enquanto tal. $\mathrm{O}$ conhecimento nesse sentido objetivo é completamente independente da afirmação de qualquer pessoa de que sabe; é independente também da crença de qualquer um, ou da disposição de assentir; ou de afirmar, ou agir. $\mathrm{O}$ conhecimento no sentido objetivo é o conhecimento sem conhecedor; é o conhecimento sem um sujeito que sabe" (p.160).

Lakatos reproduz a mesma idéia, conforme mostra o próprio Chalmers, que o cita na seqüência:

“... uma teoria pode ser pseudocientífica mesmo apesar de ser eminentemente 'plausível' e todo mundo crer nela, e ela pode ser cientificamente valiosa embora ninguém creia nela. Uma teoria pode ter um valor científico supremo ainda que ninguém a compreenda, ou nem mesmo creia nela. $\mathrm{O}$ valor cognitivo de uma teoria nada tem a ver com sua influência psicológica na mente das pessoas. Crenças, compromisso e compreensão são estados da mente humana... Mas o valor objetivo, científiço de uma teoria... é independente da mente humana que a cria ou a compreende" (p.160-161).

Como conseqüência, conclui Chalmers, para Popper e Lakatos "a história do desenvolvimento interno de uma ciência será 'a história da ciência descorporificada"' (p.161).

Kuhn também assume a idéia da importância do papel da teoria nas experiências, ou de que um sentido global de mundo participa sempre do das percepções. Critica, portanto, a possibilidade de uma linguagem neutra na observação, ou o mito de que a experiência dos sentidos é fixa e neutra. Chalmers ilustra esse ponto quando procura mostrar a dependência que a observação tem de determinada teoria, levando em conta uma objeção muito comum dos que defendem a unicidade do sentido percebido:

"Uma resposta comum à afirmação que estou fazendo sobre a observação, apoiada pelos tipos de exemplos que utilizei ${ }^{9}$, é que observadores vendo a mesma cena do mesmo lugar vêem a mesma coisa,mas interpretam o que vêem diferentemente" (p.51). E conclui de forma clara e incisiva: "O que é dado unicamente pela situação física é a imagem sobre a retina de um observador, mas um observador não tem contato perceptivo direto com essa imagem. Quando o indutivista ingênuo e muitos outros empiristas supõem que algo único nos é dado pela experiência $e$ que pode ser interpretado de várias maneiras, eles estão supondo, sem argumento e a despeito de muitas provas em contrário, alguma correspondência entre as imagens sobre nossas retinas e as experiências subjetivas que temos quando vemos (...) certamente não estou afirmando que as causas físicas das imagens sobre nossas retinas nada têm a ver com o que vemos. Entretanto, embora as imagens sobre nossas retinas façam parte da causa do que vemos, uma outra parte muito importante da causa é constituída pelo estado interior de nossas mentes ou cérebros, que vai claramente depender de nossa formação cultural, conhecimento, expectativas, etc. e não será determinado apenas pelas propriedades físicas de nossos olhos e da cena observada" (p.52).

Este ponto foi muito ressaltado por Kuhn e Chalmers, que destaca uma observação histórica de Kuhn a esse respeito, afirmando que:

"mudanças nos céus começaram a ser notadas, registradas e discutidas pelos astrônomos do Ocidente depois da proposta da teoria copernicana. Antes disso, o paradigma

\footnotetext{
' Chalmers, assim como Kuhn, refere-se a resultados de experimentos da psicologia da percepção que indicam diferenças de sentidos percebidos sobre o mesmo material de visão.
} 
aristotélico havia dito que não poderia haver mụdanças na região sobrelunar e, conseqüentemente, nenhuma mudança foi observada" (p.131).

Feyerabend (1977) também enfatiza esse ponto à luz de uma teoria gramatical aparentemente muito próxima da de Wittgenstein, como, aliás, é a desenvolvida pelo próprio Kuhn:

\begin{abstract}
“ 'a linguagem e os padrões de reação que envolvem não constituem meros instrumentos para descrever eventos (fatos, estados de coisas) mas são, também, modeladores de eventos (fatos, estados de coisas), contendose em sua 'gramática' uma cosmologia, uma visão ampla do mundo, da sociedade, da situação do homem, que influencia o comportamento, a percepção....Usuários das gramáticas marcadamente diversas são conduzidos, pelas suas gramáticas, a diferentes gêneros de observação"” (p. 349)).
\end{abstract}

Destaca-se que a presença de anomalias nas teorias científicas é um fenômeno histórico comum e não representa por si só a presença de crises teóricas. Mas, se teorias participam do sentido da percepção, se não há, pois, enunciados de observação definitivos em que se possa apoiar a ciência, a relação entre enunciados de percepção e teorias científicas torna-se muito mais complexa. $O$ exemplo mais ilustrativo é a sofisticação dos testes de "verificação" de uma teoria. Galileu anexava como apoio de sua teoria do sistema solar um instrumento de observação, o telescópio, que também implicava teoria no seu próprio uso, no caso, a óptica. Feyerabend (1977) enfatiza o quanto seu uso foi contestado na época por seus oponentes, tanto por razões teóricas (ou de interpretação), quanto de imprecisão das imagens dos primeiros telescópios. E fala do papel da especulação ou imaginação no novo tipo de experiência inaugurada por Galileu, muito distante da do senso comum ou do sentido do termo na filosofia aristotélica.

Latour e Woolgar (1992), seguindo os passos de Bachelard, salientam o quanto um laboratório de pesquisa é repleto de instrumentos que participam da construção dos fenômenos, que levam, por sua vez, ao aparecimento de novos fatos e materiais; o quanto a experiência científica distanciou-se da experiência ingênua de mundo, razão que levou Bachelard a cunhar o termo fenomenotécnica para expressá-la; e como tais instrumentos representam teoria reificada, isto é, incorporada sem mais discussão.

Tudo isso mostra que o desenvolvimento das teorias científicas traz a expansão de uma rede teórica e instrumental que impossibilita a sua falsificação no sentido restrito do termo. Como diz Feyerabend (1977), apontando para o caráter histórico-fisiológico da evidência da observação, uma teoria pode ser incompatível com a observação porque esta pode estar contaminada. Chalmers (1993) sintetiza bem esse ponto:

"Nada na lógica da situação requer que deva ser sempre a teoria a ser rejeitada na ocasião de um choque com a observação. Uma proposição de observação falível pode ser rejeitada e a teoria falível com a qual ela se choca ser mantida. É exatamente isto que estava envolvido quando a teoria de Copérnico foi mantida e a observação a olho nu de que Vênus não muda de tamanho apreciavelmente no curso do ano, inconsistente com a teoria de Copérnico, foi rejeitada. É isto também que está envolvido quando descrições modernas da trajetória da Lua são mantidas e proposições de observação referentes ao fato de que a Lua é muito maior quando está perto do horizonte do que quando está alta no céu são vistas como resultantes de uma ilusão, mesmo considerando-se que a causa da ilusão não é muito bem compreendida. A ciência abunda com exemplos de rejeição de proposições de observação e retenção de teorias com as quais elas se chocam. Contudo, por mais seguramente baseada na observação uma afirmação possa parecer estar, a possibilidade de que novos avanços teóricos revelarão inadequações nessa afirmação não pode ser descartada. Conseqüentemente, falsificações conclusivas, diretas, de teorias, não são realizáveis" (p.91). 
Na sua apresentação dos limites do falsificação, Chalmers cita, inclusive, o próprio Popper:

"A base empírica de uma ciência objetiva não tem assim nada de 'absoluto'. A ciência não repousa sobre um sólido leito pedregoso. A audaciosa estrutura de suas teorias ergue-se como se estivesse sobre um pântano. Ela é como um prédio construído sobre estacas. Estas são impulsionadas para baixo no pântano, mas não para alguma base natural ou 'dada'; e se paramos de impulsionar as estacas mais para o fundo não é porque alcançamos solo firme. Nós simplesmente paramos quando ficamos satisfeitos pelas estacas estarem suficientemente firmes para agüentar a estrutura, ao menos por um tempo... é precisamente o fato de as proposições de observação serem falíveis, e sua aceitação apenas experimental e aberta à revisão que derruba a posição falsificacionista. As teorias não podem ser conclusivamente falsificadas porque as proposições de observação que formam a base para a falsificação podem se revelar falsas à luz de desenvolvimentos posteriores" (p.94).

Correndo o risco de certa redundância, conclui-se esse ponto com outra citação de sua obra sobre as pressuposições teóricas de um enunciado observacional. Tome-se novamente o exemplo citado da previsão da localização de um suposto planeta no sistema solar.

"As premissas das quais a previsão é derivada vão incluir as afirmações interconectadas que constituem a teoria em teste, condições iniciais tais como posições anteriores do planeta e do Sol, suposições auxiliares como aquelas que possibilitam correções a serem feitas para a refração da luz do planeta na atmosfera da Terra, e assim por diante. Agora,'se a previsão que se segue desse labirinto de premissas revela-se falsa (em nosso exemplo, se o planeta não aparecer no local previsto), então tudo o que a lógica da situação nos permite concluir é que ao menos uma das premissas deve ser falsa. Isto não nos possibilita identificar a premissa errada. A teoria em teste pode estar errada, mas alternativamente pode ser uma suposição auxiliar ou alguma parte da descrição das condições iniciais que sejam responsáveis pela previsão incorreta. Uma teoria não pode ser conclusivamente falsificada, porque a possibilidade de que alguma parte da complexa situação do teste, que não a teoria ém teste, seja responsável por uma previsão errada não pode ser descartada" (p.95).

Mas a diferença entre Popper e Kuhn se acentua quando Kuhn afirma que não há passagem racional de uma teoria a outra, o que tanto Popper quanto Lakatos procuram garantir. É esse ponto que representa para ele a incomensurabilidade das teorias, pois impede sua comparação lógica ou racional:

"Ao menos para o historiador, diz Kuhn (1962, 1992), tem pouco sentido sugerir que a verificação consiste em estabelecer o acordo do fato com a teoria. Todas as teorias historicamente significativas concordaram com os fatos; mas somente de uma forma relativa (...) Faz muito sentido perguntar qual das duas teorias existentes que estão em competição adequa-se melhor aos fatos (...) Essa formulação, entretanto, faz com que a tarefa de escolher entre paradigmas pareça mais fácil e mais familiar do que realmente é (...) Nenhuma das partes aceitará todos os pressupostos não-empíricos de que o adversário necessita para defender sua posição (...) Embora cada um deles possa ter a esperança de converter $\mathrm{o}$ adversário à sua maneira de ver a ciência e a seus problemas, nenhum dos dois pode ter a esperança de demonstrar sua posição. A competição entre paradigmas não é o tipo de batalha que possa ser resolvido por meio de provas" (p.187-188).

\section{Em outros termos,}

"quando os paradigmas participam - e devem fazê-lo - de um debate sobre a escolha de 
um paradigma, seu papel é necessariamente circular. Cada grupo utiliza seu próprio paradigma para argumentar em favor desse mesmo paradigma. Naturalmente a circularidade resultante não torna esses argumentos errados ou mesmo ineficazes. Colocar um paradigma como premissa numa discussão destinada a defendêlo pode, não obstante, fornecer uma mostra de como será a prática científica para todos aqueles que adotarem a nova concepção da natureza. Essa mostra pode ser imensamente persuasiva, chegando muitas vezes a compelir à sua aceitação. Contudo, seja qual for a sua força, o status do argumento circular equivale tão-somente ao da persuasão. Para os que se recusam entrar no círculo, esse argumento não pode tornar-se impositivo, seja pela lógica, seja probabilisticamente. As premissas e os valores partilhados pelas duas partes envolvidas em um debate sobre paradigmas não são suficientemente amplos para permitir isso. Na escolha de um paradigma, - como nas revoluções políticas - não existe critério superior ao consentimento da comunidade relevante" (p.128).

Persuasão, portanto, que pode levar a uma nova forma de ver e de pensar o mundo, cuja passagem, entretanto, está mais próxima da conversão religiosa do que do convencimento racional. Isto é, a conversão completa seria uma mudança profunda na "visão" de mundo, havendo boas razões para fazê-la e a possibilidade de "tradução" de parte da linguagem do outro para o novo paradigma, mas o acordo entre os grupos rivais nesse processo de "tradução" não é fundado logicamente, porque o que está em jogo aqui não são leis, passíveis de correção no interior de cada paradigma, mas definições que fundamentam os próprios paradigmas.

Como diz Feyerabend (1977), em defesa de Kuhn (e aparentemente à luz do segundo Wittgenstein), o que está em jogo não são alternativas definidas por regras, mas as próprias regras. Em outros termos, teorias incomensuráveis podem ser refutadas apenas internamente, pois seus conteúdos não são comparáveís. Kuhn $(1962,1992)$ cita uma declaração de Max Plank, para ilustrar a situação: "ao passar em revista a sua carreira no seu Scientific Autobiography, observou tristemente que 'uma nova verdade científica não triunfa convencendo seus oponentes e fazendo com que vejam a luz, mas porque seus oponentes finalmente morrem e uma nova geração cresce familiarizada com ela" (p.191).

Alguns critérios existem, naturalmente, na escolha entre paradigmas:

"Em primeiro lugar, o novo candidato deve parecer capaz de solucionar algum problema extraordinário, reconhecido como tal pela comunidade e que não possa ser analisado de nenhuma outra maneira, Em segundo lugar, o novo paradigma deve garantir a preservação de uma parte relativamente grande da capacidade objetiva de resolver problemas, conquistada pela ciência com o auxílio dos paradigmas anteriores" (idem, p.212).

Mas esses critérios não fornecem razões suficientes para a troca de paradigmas, nem significam a possibilidade de um progresso ontológico com a substituição das teorias. Há apenas progresso na resolução de quebra-cabeças.

\section{Referências Bibliográficas}

Chalmers, A.F. (1993). O que é Ciência, afinal? São Paulo: Brasiliense.

Feyerabend, P. (1977). Contra o Método. Rio de Janeiro: Francisco Alves.

Hempel, C.G. (1981). Filosofia da Ciência Natural, $3^{\mathrm{a}}$ ed.. Rio de Janeiro: Zahar.

Kuhn, T.S. (1962/1992). A Estrutura das Revoluções Científicas, $3^{\text {a }}$. ed. São Paulo: Perspectiva.

Lakatos, I. \& Musgrave, A. (1979). A Crítica e o Desenvolvimento do Conhecimento. São Paulo: Cultrix-Edusp.

Latour, B. \& Woolgar, S. (1997). A Vida de Laboratório: a produção dos fatos científicos. Rio de 
138 Reinaldo Furlan

Janeiro: Relume Dumara.

Popper, K. (1959/1999). A Lógica da Pesquisa Cientifica. São Paulo: Cultrix.

Popper, K. (1963, s/d). El desarrollo del Conocimiento científico - Conjecturas y refutaciones. Buenos Aires: Paidos. 